\title{
AKUAPONIK SEBAGAI SARANA PEMBERDAYAAN MASYARAKAT LABUHBARU BARAT DALAM KONSEP URBAN FARMING
}

\author{
Naila Fauza ${ }^{1}{ }^{*}$, Ade Alwi Wardana ${ }^{1}$, Anna Pratiwi ${ }^{1}$, Bela Winalda ${ }^{1}$, \\ Diya Meiliza Putri ${ }^{1}$, Diara Tihanum ${ }^{1}$, Dhika Ayu Dwinda ${ }^{1}$, Hera Julia Anika ${ }^{1}$, \\ Julian Bramuli ${ }^{1}$, Muhammad Fikri Hafiz ${ }^{1}$, Muhammad Refri Fernando ${ }^{1}$ \\ ${ }^{1}$ Universitas Riau, Pekanbaru, Indonesia \\ *nailafauza@lecturer.unri.ac.id
}

\begin{abstract}
Abstrak: Kelurahan Labuhbaru Barat termasuk salah kelurahan potensial yang terletak di jantung Kota Pekanbaru, Riau. Potensi ini terlihat dari melimpahnya sumber daya alam dan manusia yang ada di kelurahan ini. Namun demikian, masyarakat Labuhbaru Barat memiliki kendala dalam pengelolaan lahan perkotaan yang sempit. Pengabdian kepada masyarakat ini berupaya untuk mengoptimalkan sumberdaya masyarakat perkotaan secara terpadu dengan konsep urban farming. Konsep ini menekankan pada kemandirian masyarakat kota dalam usaha mengembangkan pertanian. Salah satu penerapan urban farming adalah sistem akuaponik yang dapat menjadi solusi dalam pengelolaan pertanian di Kelurahan Labuhbaru Barat. Kegiatan penerapan teknologi akuaponik ini dilaksanakan oleh Tim Kukerta Balek kampong Universitas Riau pada bulan Maret-Agustus 2021 di Kelurahan Labuhbaru Barat, Kecamatan Payung Sekaki, Pekanbaru, Riau. Kegiatan pengabdian ini bertujuan untuk meningkatkan pengetahuan teknologi akuaponik melalui pembuatan media akuaponik dan sosialisasi terhadap masyarakat. Metode yang digunakan adalah Participatory Rural Apprasial (PRA), Participatory Technology Development (PTD), dan pendekatan edukatif. Tahapan kegiatan meliputi pembuatan akuaponik, pelaksanaan budidaya akuaponik, dan sosialisasi kepada para warga Kelurahan Labuhbaru Barat. Hasil pengabdian kepada masyarakat ini menunjukkan adanya peningkatan pengetahuan masyarakat kota dalam budidaya ikan dan tanaman dengan teknologi akuaponik. Masyarakat menjadi lebih memahami proses pembuatan, pemeliharaan, maupun hasil yang akan diperoleh dari penerapan teknologi akuaponik khususnya dengan menggunakan komoditas lele dan kangkung.
\end{abstract}

Kata kunci: akuaponik, pemberdayaan masyarakat, urban farming

\begin{abstract}
West Labuhbaru village is one of the potential villages located in the heart of Pekanbaru City, Riau. This potential can be seen from the abundance of natural and human resources in the village. However, the people of West Labuhbaru have constraints in managing narrow urban land. This community service program seeks to optimize urban community resources in an integrated manner with the concept of urban farming. This concept emphasizes the independence of urban communities in developing agriculture. One application of urban farming is an aquaponics system that can be a solution in agricultural management in the West Labuhbaru Village. This aquaponic technology application activity was carried out by the Balek Village Kukerta Team, Riau University in March-August 2021 in Labuhbaru Barat Village, Payung Sekaki District, Pekanbaru, Riau. This program aims to increase the participants' knowledge of aquaponics technology through the manufacture of aquaponics media and socialization to the community. The methods used were Participatory Rural Appraisal (PRA), Participatory Technology Development (PTD), and an educational approach. The activity stages include making aquaponics, implementing aquaponic cultivation, and socializing with residents of West Labuhbaru Village. The results of this program show that there is an increase in the knowledge of the city community in fish and plant cultivation with aquaponic technology. The community becomes more aware of the manufacturing process, maintenance, and the results that will be obtained from the application of aquaponics technology, especially by using catfish and water spinach commodities.
\end{abstract}

Keywords: aquaponics, community empowerment, urban farming 


\section{Pendahuluan}

Pandemi Covid-19 yang berdampak terhadap seluruh aspek kehidupan juga turut dirasakan oleh masyarakat di seluruh dunia. Kebutuhan pangan mengalami peningkatan harga akibatnya kesulitan pangan yang dialami masyarakat. Beberapa kebutuhan pokok juga sempat dikhawatirkan akan mengalami kelangkaan akibat jalur-jalur distribusi yang ditutup. Terutama di wilayah perkotaan sendriri salah satunya adalah kota Pekanbaru yang dimapa pada tahun 2020, pemerintah Provinsi Riau mulai menyiapkan langkah-langkah sistematis untuk memastikan ketersediaan pangan yang cukup. Isu pangan menjadi persoalan krusial bagi seluruh lapisan masyarakat salah satunya adalah masyarakat perkotaan yang dimana masalah utama di daerah kota adalah ketahanan pangan yang dimana kebutuhan pangan semakin lama akan meningkat tetapi lahan pertanian tidak mampu mencukupi kebutuhan tersebut (Rokhmah, Ammatillah, \& Sastro, 2014). Oleh karena itu, pengelolaan sumber daya yang tersedia harus mampu ditangani secara optimal terutama di masa krisis seperti sekarang ini. Produk yang dihasilkan dapat dikonsumsi oleh skala rumah tangga atau dijual, namun manfaat sosial dan ekologinya tetap dipertahankan (Kehlenbeck and Maass 2004).

Salah satu cara yang dapat dilakukan oleh masyarakat diperkotaan untuk meningkatkan ketahanan panganan dengan menggunakan budidaya akuaponik. Hal ini dikarenakan instalasi akuaponik tidak membutuhkan lahan yang besar dimana dengan media tanam berukuran $3 \mathrm{~m}$ x 6 m mampu memproduksi sekitar 1.100 sayuran dan $180 \mathrm{~kg}$ ikan. Sayuran tersebut bisa dipanen setiap 30-40 hari, sedangkan ikan (tilapia atau nila) dapat dipanen setiap 6 bulan (Sungkar 2015) pemanfaatan lahan pekarangan dapat menjadi solusi dari kelangkaan pangan di masyarakat. Aplikasi budidaya akuaponik yang menggabungkan teknologi budidaya perikanan dan pertanian diharapkan dapat memenuhi kebutuhan pangan masyarakat yang kemudian menghasilkan kemandirian pangan rumah tangga. Prinsip dasar akuaponik ialah hemat dalam pemanfatan lahan dan air, serta meningkatkan hasil usaha melalui pemanfaatan makanan dari sisa pakan dan daya tahan ikan sebagai nutrisi untuk tanaman air serta merupakan salah satu upaya sistem budidaya yang termasuk ramah lingkungan (Zidni et al., 2013). Teknologi ini dinilai sangat praktis dalam menghasilkan keuntungan ganda dari hasil ikan dan sayuran secara bersamaan. Akuaponik dapat dilakukan dalam skala kecil hingga besar tergantung dari penggunaan yang akan diterapkan.

Melihat dari fleksibilitas akuaponik sebagai potensi kewirausahaan, masyarakat di Kelurahan Labuhbaru Barat dapat memberdayakan teknologi akuaponik ini. Pemberdayaan bertujuan untuk memperkuat kemampuan masyarakat, agar mereka dapat berpartisipasi secara aktif dalam proses pembangunan secara keseluruhan, diutamkan pembangunan yang ditawarkan oleh enterprenur dan atau pihak luar (Manik et al., 2020). Pemberdayaan masyarakat melalui teknologi tepat guna ini memberikan peluang untuk meningkatkan perekonomian masyarakat di masa pandemi ini.

Kelurahan Labuhbaru Barat merupakan salah satu Kelurahan yang terdapat di Kecamatan Payung Sekaki, Kota Pekanbaru, Riau. Kelurahan ini terletak di Kecamatan Payung Sekaki yang memiliki luas $43.24 \mathrm{~km}^{2}$ (Dinas Komunikasi Informatika Statistik dan Persandian Kota 
Pekanbaru, 2020). Kelurahan Labuhbaru Barat merupakan yang terluas dengan $24.100 \mathrm{~km}$ dimana mata pencaharian masyarakatnya di bidang UMKM, Peternakan, dan Perkebunan. Berdasarkan dari observasi lapangan, keterbatasan lahan di Kelurahan Labuhbaru Barat menyulitkan masyarakat untuk melakukan kegiatan bercocok tanam. Melalui bercocok tanam, warga Labuhbaru Barat diharapkan dapat memenuhi kebutuhan dasar pangan. Hidroponik merupakan salah satu alternatif bercocok tanam yang cocok di lahan yang sempit.

Pengelolaan budidaya akuaponik termasuk cara efisien karena sistem akuaponik adalah sistem terintegrasi antara akuakultur dan hidroponik, limbah budidaya ikan berupa sisa metabolisme dan sisa pakan dimanfatakan untuk pupuk tanaman (Stathopoulo et al., 2018). Dengan prinsip efektifitas itu, dapat menghemat biaya usaha tani sehingga dapat meningkatkan kesejahteraan masyarakat. Tujuan penggunaan teknologi akuaponik yaitu menawarkan solusi alternatif melalui pemanfaatan lahan sempit perkotaan untuk mengembangkan pertanian serta kemandirian pangan di masa pendemi. Selain itu penggunaan prinsip akuaponik merupakan cara yang tepat untuk meningkatkan pemberdayaan masyarakat. Urban Farming atau pertanian kota merupakan salah satu kunci pemberdayaan untuk sistem pangan masyarakat yang berkelanjutan. Apabila dirancang secara tepat akan dapat mengurangi permasalahan kesulitan pangan. Dengan kata lain, apabila pertanian perkotaan dikembangkan secara terpadu merupakan solusi untuk mewujudkan pembangunan kota berkelanjutan (Fauzi, Ichniarsyah, \& Agustin, 2016). Maka dari itu penerapan akuaponik sebagai pemberdayaan di masyarakat kota merupakan cara alternatif untuk meberdayakan masyarakat kota dari pemenuhan pangan dilahan perkotaan yang sempit.

\section{Metode}

Dalam penerapannya akuaponik terdiri dari dua bagian utama. Bagian utama tersebut adalah bagian akuatik (air) untuk pemeliharaan hewan air dan bagian hidroponik untuk menumbuhkan tanaman (Febrianti et al., 2020). Kegiatan penerapan teknologi akuaponik oleh Tim Kukerta Balek kampung Universitas Riau tahun 2021 dilaksanakan pada bulan MaretAgustus 2021 di Kelurahan Labuhbaru Barat, Kecamatan Payung Sekaki, Kota Pekanbaru, Riau. Tahapan kegiatan yang dilakukan antara lain adalah pembuatan akuaponik, pelaksanaan budidaya akuaponik, dan sosialisasi kepada para warga Kelurahan Labuhbaru Barat. Kegiatan ini dilaksanakan dengan melibatkan RW 01 Kelurahan Labuhbaru Barat, beserta Ibu Nurma selaku pemilik lahan percontohan akuaponik dan dikelola oleh Peserta Kukerta Balek Kampung Labuhbaru Barat 2021 Universitas Riau. Pelaksanaan kegiatan menggunakan metode yang melibatkan warga RW 01 Kelurahan Labuhbaru Barat, yaitu:

1. Participatory Rural Aprasialyang masyarakat terlibat dalam keseluruhan kegiatan. Melalui sosialisasi awal dengan mengundang masyarakat untuk terlibat dalam membuatan akuaponik. Tujuanya untuk daya tarik warga yang ingin mengembangkan akuaponik.

2. Participatory Technology Development yang memanfaatkan teknologi tepat guna berintegrasi ilmu pengetahuan dan kearifan lokal yaitu akuaponik. 
3. Pendekatan sosialisasi untuk menyalurkan ilmu pengetahuan dan pendidikan untuk pemberdayaan masyarakat (educative). Warga yang tertarik mengikuti kegiatan diberikan pendampingan dalam membuat akuaponik.

Instrumen yang digunakan untuk melihat peningkatan pengetahuan tentang akuaponik pada masyarakat Kelurahan Labuhbaru Barat adalah lembar wawancara dengan tiga item pertanyaan (pengetahuan dasar tentang akuaponik, penggabungan budidaya tanaman dan ikan, dan pemupukan dengan kotoran ikan).

Pembuatan Akuaponik dirancang secara sederhana agar dapat menjadi sarana pembelajaran bagi warga RW 01 Labuhbaru Barat. Berdasarkan kesepakatan dengan ketua RW 01 Kelurahan Labuhbaru Barat, akuaponik dengan ukuran $1 \times 1 \mathrm{~m}$ dibangun di pekarangan rumah Ibu Nurma yang sudah cukup berpengalaman dalam budidaya agrikultur. Bahan yang dibutuhkan dalam proses pembuatan akuaponik yaitu Pipa 3/4" 1m, Pipa 3" 1m, Kayu, Botol $1 \mathrm{~L}$ 16 buah, Aqua gelas 32 buah, Terpal ukuran M, Selang akuarium 5m, Selang 1/2" 1m, Pompa air, Klem pipa, Lem pipa. Alat yang dibutuhkan dalam proses pembuatan akuaponik antara lain Gergaji pipa/hole saw, paku, palu, meteran,dan gergaji.

Sistem yang digunakan dalam pembuatan ini menggunakan Deep Flow Technique (DFT) yaitu sistem penanaman dengan memanfaatkan aliran air secara terus menerus sebagai penyalur nutrisi. DFT adalah metode budidaya hidroponik yang dimodifikasi, dikembangkan dan digunakan di Jepang sejak tahun 1973, yang membutuhkan air dan nutrisi dalam jumlah besar (Kao et al., 1991) . kelebihan Sistem DFT pada saat aliran arus listik padam maka makanan tetap tersedia. Keunggulan lainnya adalah hematnya pemakaian listrik dan tanaman tidak mudah kering/mati. Desain akuaponik disajikan dalam gambar 1 dibawah ini.

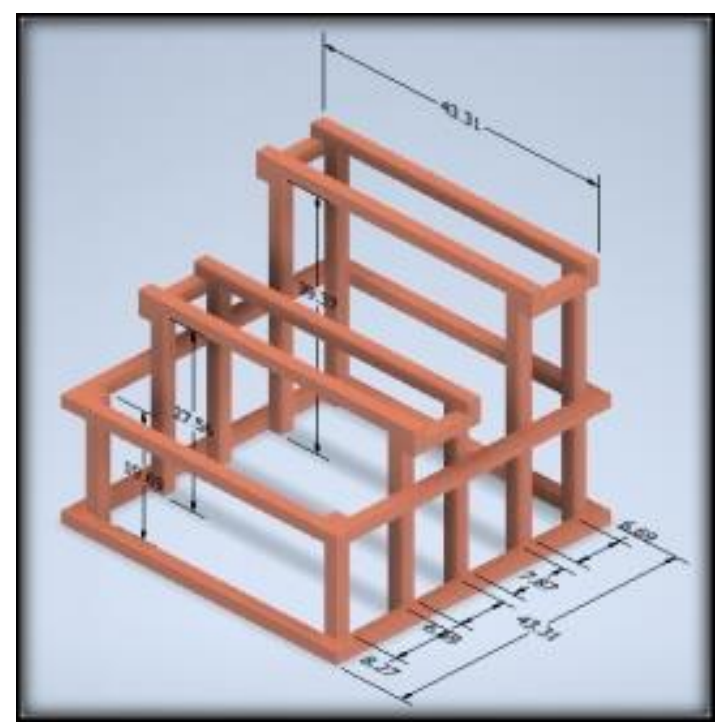

Gambar 1. Desain Akuaponik di Kelurahan Labuhbaru Barat

Kerangka akuaponik yang telah selesai dapat langsung dipersiapkan untuk media budidaya ikan dan tanaman. Komoditas ikan yang dikembangkan yaitu Ikan Lele. Benih ikan lele yang akan dibudidayakan berkisar ukuran 7-8 cm dengan keadaan aktif bergerak dan responsif. Sebelum dimasukkan kedalam media akuaponik, pompa dihidupkan selama 3 hari 
nonstop 24 jam dengan dialiri air terus menerus agar terbentuk bakteri pengurai secara alamiah.

Persiapan tanaman juga dilakukan dengan penyemaian bibit tanaman. Tanaman yang digunakan dalam akuaponik ini adalah bibit kangkung. Untuk melihat bibit yang bagus, bibit kangkung direndam dalam air agar dapt terlihat bibit yang mengapung atau tenggelam. Kemudian bibit yang telah terseleksi dimasukkan kedalam media tanam akuaponik. Alur kegiatan budidaya akuaponik di Kelurahan Labuhbaru Barat tersaji dalam tabel 1 di bawah ini. Sementara Media akuaponik yang telah siap pakai telampir dalam Gambar 2.

Tabel 1. Alur Kegiatan Budidaya Akuaponik

\begin{tabular}{clc}
\hline No & \multicolumn{1}{c}{ Kegiatan } & Hari ke- \\
\hline 1 & Persiapan media & $1-7$ \\
2 & Penyemapian bibit tanaman & $1-7$ \\
3 & Pengisian air & $1-14$ \\
4 & Penebaran benih ikan dan tanaman & $8-14$ \\
5 & Pemberian pakan & 16 -panen \\
\hline
\end{tabular}

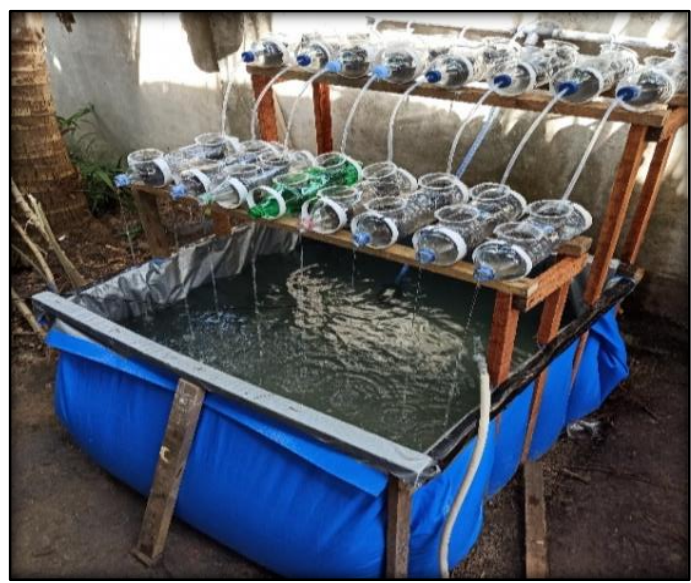

Gambar 2. Akuaponik yang telah selesai

Akuaponik yang telah selesai ditanami bibit kangkung dan ditebarkan bibit lele mulai secara intensif di perhatikan untuk melihat apakah ada kendala maupun ketidaksesuaian air terhadap ikan lele. Aliran air yang telah terpompa dengan baik mengantarkan kotoran yang telah diproduksi ikan kedalam media tanam kangkung.

Setelah mempersiapkan media akuaponik, kegiatan pengenalan teknologi akuaponik (Participatory Rural Aprasial, Participatory Technology Develpoment, Sosialisasi, dan Wawancara) dilaksanakan pada pertemuan warga RW 01 Kelurahan Labuhbaru Barat bertepatan dengan acara arisan warga setempat. Pada kesempatan ini, peserta kukerta menyampaikan materi antara lain pengertian teknologi akuaponik, prinsip kerja akuaponik, keunggulan akuaponik, persiapan budidaya akuaponik, pembuatan akuaponik, pemilihan bibit tanaman dan ikan, pemiliharaan akuaponik dan manajemen teknologi akuaponik. Pengedukasian masyarakat Labuhbaru Barat dilakukan dengan pemaparan presentasi dan penampilan video pembuatan akuaponik Sosialisasi teknologi akuaponik kepada warga RW 01 Kelurahan Labuhbaru Barat tersaji dalam gambar 3. 

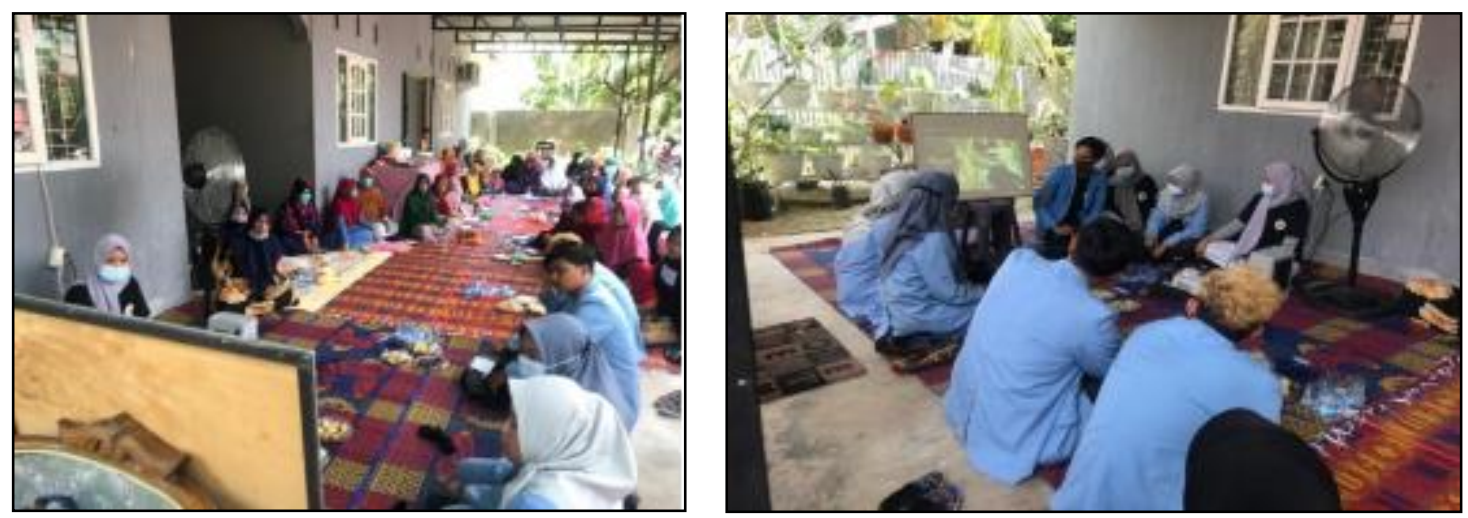

Gambar 3. Sosialisasi Akuaponik kepada warga RW 01 Kelurahan Labuhbaru Barat

\section{Hasil dan Pembahasan}

Hasil dan ketercapaian yang diharapkan adalah peningkatan pengetahuan masyarakat Kelurahan Labuhbaru Barat dalam budidaya akuaponik serta pertumbuhan ikan dan tanaman yang diharapkan akan menghasilkan keuntungan ekonomi dan kemandirian pangan pada masyarakat Labuhbaru Barat. Merujuk terhadap hasil ini, kami mengambil beberapa rujukan jurnal yang pernah membahas akuaponik dengan teknik sosialisasi yang sama.

Budidaya gabungan Ikan dan Sayuran melalui Metode Akuaponik Di Desa Serut Kecamatan Panti Kabupaten Jember (Dewanti 2019) disebutkan bahwa budidaya akuaponik dipilih sebagai program pengembangan desa karena dinilai karena mempunyai potensi tinggi untuk pengembangan sayuran hidroponik ditinjau dari tata letak, kepedulian dan kemandirian masyarakatnya dan berjiwa kewirausahaan. Disisi lain, hasil observasi ditemukan pula sebagian penduduk di Dusun Karang Anom desa Serut Kecamatan Panti memiliki usaha budidaya ikan yang telah berjalan beberapa tahun terakhir.

Selain itu, Penyuluhan Akuaponik Dalam Masa Pandemi COVID-19 di RT. 003, RW. 006 Desa Kabasiran (Manik et al., 2020) menyatakan dalam memberikan informasi atau pengetahuan tambahan mengenai pengembangan kemampuan masyarakat dalam pembudidayaan akuaponik sebagai upaya untuk melakukan usaha di masa pandemi. Berikut adalah hasil dan ketercapaian yang diperoleh dari Tim Kukerta Balek Kampung UNRI Kelurahan Labuhbaru Barat tahun 2021.

\section{Peningkatan Pengetahuan Masyarakat Kelurahan Labuhbaru Barat tentang Teknologi Akuaponik}

Pengetahuan masyarakat tentang teknologi akuaponik menjadi salah satu yang dihasilkan. Berdasarkan hal tersebut, pemahaman masyarakat sebelum dan sesudah sosialisasi dapat menjadi indikator dari ketercapaian sasaran pengabdian. Pengolahan akuaponik yang praktis dan ekonomis menjadi sarana budidaya yang menarik terutama bagi kalangan ibu rumah tangga. Masyarakat Labuhbaru Barat yang berdomisili di perkotaan dapat memanfaatkan lahan sempit yang tersedia dengan lebih efektif melalui teknologi akuaponik. Gambaran masyarakat hanya terbatas pada mengenal istilah-istilah pertanian namun dalam proses pembuatan pemahaman masyarakat masih sangat rendah. Hasil pengukuran pengetahuan menunjukkan 
bahwa terjadi peningkatan tentang pengenalan istilah akuaponik terhadap masyarakat sebesar $35 \%$. Dengan antusiasme masyarakat mengikuti sosialisasi, masyarakat jadi lebih mengetahui tentang gambaran proses pembuatan, pemeliharaan, maupun hasil yang akan diperoleh dengan menggunakan komoditas lele dan kangkung. Peningkatan pengetahuan tentang akuaponik disajikan pada grafik 1 .

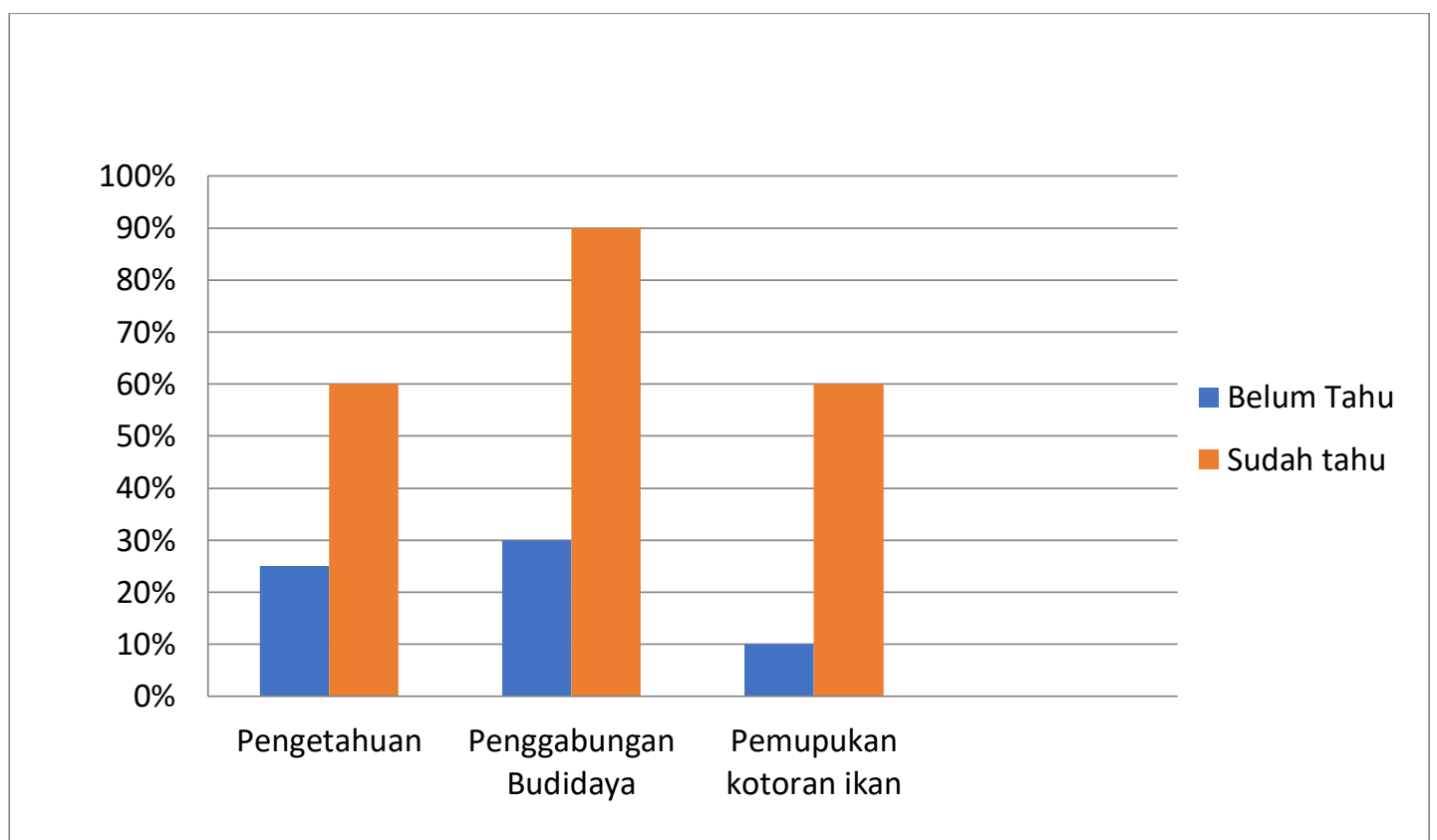

Grafik 1. Peningkatan pengetahuan tentang akuaponik masyarakat Keluruhan Labuhbaru Barat

Pada saat sebelum dilaksanakan sosialisasi teknologi akuaponik, masyarakat sudah mengenal budidaya hidroponik. Hidroponik dinilai cukup sulit dan cenderung mahal untuk dijadikan peluang bisnis skala rumah tangga sehingga masyarakat kurang minat untuk memberdayakan teknologi tersebut. Selain itu, pengetahuan terhadap konsep yang menggabungkan budidaya ikan dan tanaman masih sangat minim diketahui oleh masyarakat. Mengetahui masyarakat cukup familiar dengan konsep hidroponik, dalam sosialisasi ini lebih ditekankan dalam penggabungan budidaya ikan dan tanaman secara simbiotik di teknologi akuaponik. Hasil dari pengukuran pengetahuan masyarakat mencapai $60 \%$. teknologi akuaponik yang dapat dihasilkan dengan memanfaatkan bahan-bahan sisa rumah tangga menjadi saya tarik tersendiri bagi masyarakat. Akuaponik menjadi sarana alternatif untuk bercocok tanam dalam satu media. Selain dari pengenalan dan proses pembuatan akuaponik, masyarakat jadi lebih paham terhadap manfaat kotoran ikan bagi tanaman. Hasil metabolisme ikan yang sering menimbulkan masalah karena aroma yang tidak sedap serta kolam menjadi kotor ternyata dapat memberikan manfaat. Sisa pakan yang ditebar di kolam yang tidak dimakan oleh ikan yang menimbulkan endapan di kolam dapat dimanfatkan. Kedua limbah yang berasal dari hasil budidaya di kolam ikan tersebut dapat dimanfaatkan untuk akuaponik. Sistem akuaponik dalam prosesnya menggunakan air dari kolam ikan, kemudian disalurkan melalui pipa kemudian diteruskan ke tanaman yang akan dibudidayakan. 
Solusi ini tentunya dapat diimplementasikan untuk menangani permasalahan yang ada di Kelurahan Labuhbaru Barat. Keuntungan dari hasil panen sayuran yang dibudidayakan melalui akuaponik adalah tanaman lebih hijau, awet, segar dan tidak mudah kuning. Selain itu, sayuran menjadi lebih sehat karena bersifat organik. Hasil pengukuran terhadap peningkatan pengetahuan terhadap kotoran ikan menjadi $60 \%$.

\section{Hasil Pertumbuhan Budidaya Akuaponik}

Hasil luaran yang diperoleh pada kegiatan pengabdian Kukerta Labuhbaru Barat Universitas Riau 2021 adalah hasil pertumbuhan ikan dan kangkung yang signifikan. Sejak hari ke-8 pasca penanaman, tanaman kangkung mulai muncul dari permukaan tanah sekitar kirakira $2 \mathrm{~cm}$. Sementara benih ikan belum terlalu terlihat perkembangan yang berarti sejak ditaburkan ke kolam. Pertumbuhan kangkung terus meningkat saat dicek terakhir kali dengan tinggi sekitar $15 \mathrm{~cm}$. Di tingkatan pertama, tanaman kangkung cenderung lebih tinggi dibanding tingkat keduanya. Meskipun begitu, tanaman kangkung terlihat sangat subur dan berkembang dengan baik. Pertumbuhan ikan lele juga mengalami perubahan selama 2 minggu sejak ditabur. Ikan lele terlihat lebih besar dibanding sebelumnya dengan konsumsi pangan yang lebih banyak. Kondisi pertumbuhan akuaponik dapat dilihat pada Gambar 4.

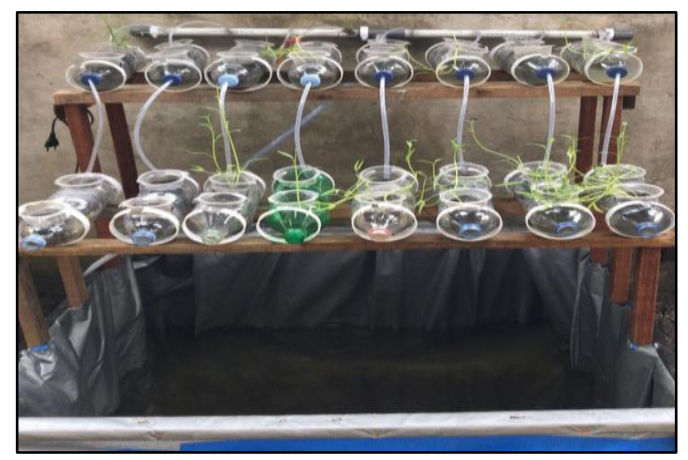

Gambar 4. Hasil pertumbuhan akuaponik

Pertumbuhan kangkung yang sangat baik disambut antusias oleh Bapak Ketua RW 01 Kelurahan Labuhbaru Barat. Warga secara berkala melihat pertumbuhan akuaponik karya Tim Kukerta dengan mengunjungi pelataran Ibu Nurma. Setelah memastikan seluruh kebutuhan akuaponik siap guna, peserta kukerta melakukan penyerahan kepada Ketua RW 01 Kelurahan Labuhbaru Barat agar akuaponik dapat terpelihara dengan baik. Penyerahan akuaponik kepada Ketua RW 01 terlapir dalam gambar 5.

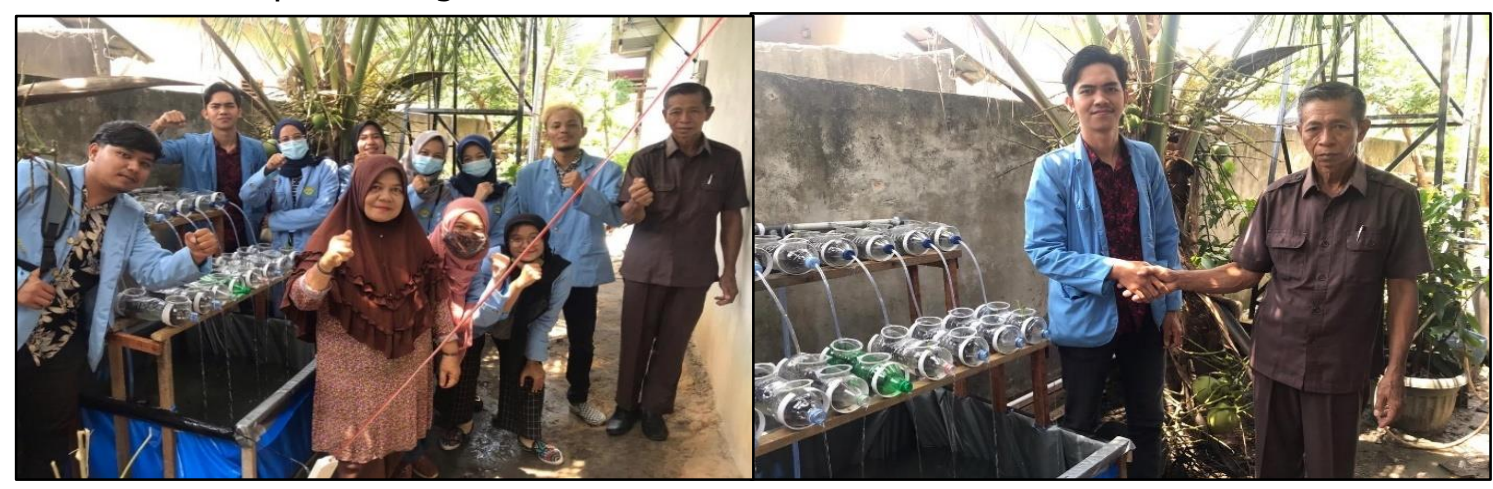

Gambar 5. Penyerahan akuaponik kepada ketua RW 01 Kelurahan Labuhbaru Barat 
Pertumbuhan kangkung dan ikan lele yang sangat baik, akuaponik di Kelurahan Labuhabaru Barat ini dapat di panen dalam 3 bulan kedepan. Hasil yang akan didapatkan adalah panen organik yang kaya nutrisi karena tidak menggunakan pupuk kimia maupun pestisida. Tanaman dan ikan yang didapatkan akan sangat terjamin kualitasnya, sehingga budidaya akuaponik ini akan sangat menguntungkan dari sisi praktis dan ekonomisnya. Hasil panen yang akan diperoleh dapat dikonsumsi secara pribadi maupun dijual dengan kualitas organik dengan harga yang cukup mahal. Diharapkan dengan pertumbuhan ini, hasil panen yang akan didapatkan akan mendorong kemandirian pangan warga Kelurahan Labuhbaru Barat sekaligus menjadi solusi dari persoalan ekonomi dan pangan di era pandemi covid-19 seperti sekarang ini.

\section{Kesimpulan}

Teknologi akuaponik melalui pemberdayaan masyarakat memberikan pengetahuan dan keterampilan kepada mesyarakat. Pengetahuan masyarakat terhadap akuaponik menjadi meningkat dengan diadakannya sosialisasi teknologi akuaponik kepada masyarakat Labuhbaru Barat. Dengan adanya akuaponik yang memiliki fungsi ganda pada budidaya tanaman dan ternak ikan, masyarakat dapat memperoleh keuntungan berlebih hanya dengan satu media. Akuaponik sendiri juga dapat dikembangkan dalam ranah yang lebih besar sebagai bisnis alternatif masyarakat yang tentunya akan menghasilkan tanaman organik yang berdaya jual tinggi dan ikan yang segar. Dengan keuntungan yang akan diperoleh dari teknologi akuaponik, masyarakat merasa antusias untuk lebih mengembangkan teknologi tepat guna seperti ini agar mendukung konsep urban farming yang sedang digebyarkan oleh pemerintah setempat.

\section{Ucapan Terima Kasih}

Kami ingin mengungkapkan banyak terima kasih kepada para pihak yang membantu kami selama pelaksanaan kegiatan pengabdian kami adapun ucapan terima kasih ini ditujukan kepada LPPM sebagai wadah pengabdian kukerta 2021, Pak Wahyu Nofiyandri, M.Pd selaku lurah Labuhbaru Barat yang bersedia memberikan tempat untuk melakukan kegiatan pengabdian ini, Ibu Nurma yang telah mengizinkan kami untuk membuat proyek kami di tempatnya dan juga bersedia meluangkan waktu untuk membantu dalam pengabdian. Terakhir adalah terima kasih kepada semua anggota kami yang selalu bekerja keras untuk membuat kegiatan pengabdian ini berhasil.

\section{Referensi}

Dewanti, P. (2019). "Budidaya Terpadu Ikan Dan Sayuran Melalui Metode Akuaponik Di Desa Serut Kecamatan Panti Kabupaten Jember." Warta Pengabdian 13(4):164. doi: 10.19184/wrtp.v13i4.13766.

Fauzi, A. R., Ichniarsyah, A. N., \& Agustin, H. (2016). Pertanian perkotaan: urgensi, peranan, dan praktik terbaik. Jurnal Agroteknologi, 10(1), 49-62.

Febrianti, D., Putra, G., Handayani, S., \& Masykur, M. (2020). MEMBANGUN BANGSA DARI DESA MELALUI SISTEM AKUAPONIK DITENGAH PANDEMI COVID 19. LOGISTA-Jurnal IImiah Pengabdian kepada Masyarakat, 4(2), 450-456.

Kao, T. C., Hsiang, T., \& Changhua, R. O. C. (1991). The dynamic root floating hydroponic technique: 
Transformasi: Jurnal Pengabdian Masyarakat, Vol. 17, No. 2, Desember 2021: 269-278

year-round production of vegetables in roc on Taiwan. Taipei, Taiwan: ASPAC Food \& Fertilizer Technology Center.

Kehlenbeck, K., and B. L. Maass. (2004). "Crop Diversity and Classification of Homegardens in Central Sulawesi, Indonesia." Agroforestry Systems, 63(1), 53-62. doi: 10.1023/B:AGFO.0000049433.95038.25.

Manik, C. D., Effendy, A. A., Rahayu, R. S., Noviyanti, I., \& Farida, S. I. (2020). PENYULUHAN AQUAPONIK DALAM MASA PANDEMI COVID-19 DI RT. 003, RW. 006 DESA KABASIRAN. Jurnal Abdimas Tri Dharma Manajemen, 1(3), 103-110.

Rokhmah, N. A., Ammatillah, C. S., \& Sastro, Y. (2014). Vertiminaponik, mini akuaponik untuk lahan sempit di perkotaan. Buletin Pertanian Perkotaan, 4(2), 14-22.

Sungkar, M. (2015). Akuaponik Ala Mark Sungkat. Pertama. edited by A. D. S. Jakarta: PT AgroMedia Pustaka.

Zidni, I., Hermawati, T., Liviawaty, E. (2013). Pengaruh Padat Tebar Terhadap Pertumbuhan Benih Lele Sangkuriang (Clarias Gariepinus) Dalam Sistem Akuaponik. Jurnal Perikanan Kelautan $4(4): 315-24$. 